\title{
Heterogeneity of proteinases from the hyperthermophilic archaeobacterium Pyrococcus furiosus
}

\author{
Helen Connaris, ${ }^{1}$ Don A. Cowan, ${ }^{1 *}$ and Richard J. SharP ${ }^{2}$ \\ ${ }^{1}$ Department of Biochemistry, University College London, Gower Street, London WCIE 6BT \\ ${ }^{2}$ Division of Biotechnology, Centre for Applied Microbiological Research, Porton Down, Wiltshire SP4 OJG
}

(Received 4 September 1990; revised 31 December 1990; accepted 9 January 1991)

\begin{abstract}
Intracellular and extracellular samples from the extremely thermophilic archaeobacterium Pyrococcus furiosus showed the presence of multiple active proteinases. Using gelatin-containing SDS-PAGE, up to 13 activity bands were visualized with apparent molecular masses of between 66 and $135 \mathrm{kDa}$. Characterization studies revealed these bands to be due to discrete polypeptides, and not artefacts. Results from gel permeation chromatography, sucrose density gradient centrifugation and non-denaturing PAGE suggested that some of these proteolytic polypeptides may exist as active aggregates either in vivo or in vitro before being dissociated by SDS to active monomers.
\end{abstract}

\section{Introduction}

The ability for extreme thermophiles, most of which belong to the Third Primary Kingdom of the Archaeobacteria, to survive temperatures of around $80^{\circ} \mathrm{C}$ and above is critically dependent on the structure and function of cellular components. Enzymes from these organisms are generally capable of withstanding high temperatures and exhibit a high degree of resistance to denaturing reagents, organic solvents and other deleterious influences (Veronese et al., 1984; Owusu \& Cowan, 1989). It is generally accepted that protein stability in these extreme thermophiles results from modifications to protein structure, such as the addition of hydrogen bonds and ionic bonds, generated by subtle differences in the amino acid sequence. Enhancement of thermal stability can also occur through improved rigidity of the more thermolabile regions of the protein structure, due to an extrinsic influence of metal ions, as with $\mathrm{Co}^{2+}$ for Sulfolobus solfataricus aminopeptidase (Hanner et al., 1990) and $\mathrm{Ca}^{2+}$ for Thermus aquaticus proteinase (Cowan \& Daniel, 1982). Despite these examples of extrinsic stabilization, most proteins from extreme thermophiles are of high intrinsic molecular stability [e.g. the extracellular proteinase archaelysin from the archaeobacterium Desulfurococcus (Cowan et al., 1987), the acid proteinase from Sulfolobus acidocaldarius (Lin \& Tang, $1990)$ and the hydrogenase from the hyperthermophilic archaeobacterium Pyrococcus furiosus (Bryant \& Adams, 1989)]. Proteinases from extremely thermophilic archaeobacteria are all highly thermostable. In other respects, these enzymes show a diversity of characteristics typical of eubacterial proteinases (Cowan et al., 1987).

The extremely thermophilic archaeobacterium Pyrococcus furiosus, isolated by Fiala \& Stetter (1986), is a heterotrophic organism which grows optimally at $100{ }^{\circ} \mathrm{C}$ under strictly anaerobic conditions. Five intracellular proteinases have been previously identified from this hyperthermophile (Blumentals et al., 1990; Eggen et al., $1990)$, with an SDS-resistant proteinase $(66 \mathrm{kDa})$ purified to homogeneity (Blumentals et al., 1990). In this paper, we present further data on the heterogeneity of the proteinases.

\section{Methods}

Growth conditions. Pyrococcus furiosus (DSM 3638) was grown anaerobically in 11 Duran bottles at $98^{\circ} \mathrm{C}$ as described by Fiala \& Stetter (1986). For the production of intracellular proteinases, cells were harvested after a $17 \mathrm{~h}$ incubation. Cell pellets were collected by centrifugation $(50000 \mathrm{~g}$ for $15 \mathrm{~min})$, washed, and resuspended in $0.01 \mathrm{M}-\mathrm{NaH}_{2} \mathrm{PO}_{4} / \mathrm{Na}_{2} \mathrm{HPO}_{4}$ buffer, $\mathrm{pH} 7.5$. Cell-free extracts for gel permeation chromatography and sucrose density gradients were prepared by sonicating cells for three $1 \mathrm{~min}$ bursts with $30 \mathrm{~s}$ intervals using a Soniprep Sonicator. The cell lysate was then centrifuged for $30 \mathrm{~min}$ at $30000 \mathrm{~g}$ to remove cell debris. Otherwise, aliquots of culture $(1 \mathrm{ml})$ were centrifuged at high speed in an MSE Microcentaur centrifuge and cell pellets were washed, resuspended in phosphate buffer $(100 \mu \mathrm{l})$ and lysed by the addition of an equal volume of SDS sample buffer $(4 \%$ (w/v) SDS $/ 20 \%(w / v)$ glycerol $/ 10 \%(w / v)$ mercaptoethanol with bromophenol blue). For extracellular proteinases, cell-free culture supernatants were obtained after harvesting and used directly. 
Cells and supernatants were either used immediately or stored at $-70^{\circ} \mathrm{C}$.

Proteinase assay. Proteinase activity was determined by the hydrolysis of azocasein (Sigma) as described by Cowan et al. (1987).

Substrate-containing SDS-PAGE. Discontinuous SDS-PAGE was performed according to Laemmli (1970), except that the separation gel $(10 \%)$ contained $0.01 \%$ gelatin (Type I, porcine skin) or casein (purified; Sigma) and $0.1 \%$ SDS. The stacking gel $(5 \%)$ also contained $0.1 \%$ SDS. Protein samples $(75 \mu \mathrm{l})$ and known molecular mass markers $(50 \mu 1)$ were mixed with an equal volume of SDS sample buffer (Laemmli, 1970) and boiled for 5-10 min before loading on to slab gels $(20 \times 16 \times 1.5 \mathrm{~mm})$. Electrophoresis was performed at $45 \mathrm{~mA}$ constant current using an LK B Vertical Electrophoresis Unit with an LKB 2197 Power Supply.

After electrophoresis, gels were gently shaken at room temperature for $2 \mathrm{~h}$ in two changes of aqueous $2.5 \%(\mathrm{w} / \mathrm{v})$ Triton X-100 (Horie et al., 1984), then incubated for $1 \mathrm{~h}$ at $90^{\circ} \mathrm{C}$ in $0.1 \mathrm{M}$-HEPES $(\mathrm{N}-2-$ hydroxyethylpiperazine- $N^{\prime}$-2-ethanesulphonic acid) buffer, $\mathrm{pH} 7.5$ $\left(90^{\circ} \mathrm{C}\right)$. After incubation, gels were immediately fixed with $50 \%(\mathrm{w} / \mathrm{v})$ TCA for 30-60 mins before staining with Coomassie Blue G250. Gels were then destained overnight in methanol:acetic acid:water $(3: 2: 35$, by vol.). Unstained bands, indicating proteolytic activity, were recorded by photography.

Quantitative analysis of data. Negatives of Polaroid photographs of substrate-containing gels were scanned using an Ultrascan XL Laser Densitometer (LK B Instruments). Proteinase activity was determined by integration of peak area for each band.

Native gels. Non-denaturing PAGE was performed on slab gels of different acrylamide concentrations (up to $10 \%$ ) to determine the molecular masses of the proteinases. Native gels were prepared (Clarke, 1964) and electrophoresed as before. After electrophoresis, gels were immersed in a solution of $1 \%$ gelatin in $0 \cdot 1 \mathrm{M}$-HEPES, $\mathrm{pH} 8 \cdot 3$, and gently shaken for $1 \mathrm{~h}$. The gels were then incubated for $1-3 \mathrm{~h}$ at $90{ }^{\circ} \mathrm{C}$ before being fixed with $50 \%(w / v)$ TCA. Gels were stained and destained as before.

Sucrose gradient centrifugation. Sucrose gradients $[6-30 \%(\mathrm{w} / \mathrm{v})$ sucrose in distilled water] were prepared as described (Martin \& Ames, 1961). Cell extract and culture supernatant samples $(500 \mu \mathrm{l})$ were layered on top of the gradients together with known molecular mass markers $(0.25 \mathrm{mg}$ of $\beta$-amylase and bovine serum albumin in $50 \mu \mathrm{l}$ of distilled water). The samples were centrifuged at $208000 \mathrm{~g}$ for $24 \mathrm{~h}$ at $20{ }^{\circ} \mathrm{C}$ in an L-7 Beckman Ultracentrifuge. The contents were removed by inserting a capillary tube to the bottom of each tube and withdrawing the contents using a peristaltic pump. Fractions $(0.5 \mathrm{ml})$ were collected. Protein was monitored spectrophotometrically at $280 \mathrm{~nm}$ and proteinase activity was determined using substrate PAGE. Molecular masses were calculated using the equation $s_{1} / s_{2} \times$ $\left(\mathrm{mm}_{1} / \mathrm{mm}_{2}\right)^{2 / 3}$, where $\mathrm{s}_{1} / \mathrm{s}_{2}$ is the partial specific volume, $\mathrm{mm}_{1}$ is the molecular mass of the unknown protein and $\mathrm{mm}_{2}$ is the molecular mass of the known standard (Martin \& Ames, 1961).

Fast protein liquid gel permeation chromatography. Samples of $P$. furiosus cell extracts $(200 \mu \mathrm{l})$ were applied to a Superose $12 \mathrm{HR} 10 / 30$ column (Pharmacia). The column was pre-equilibrated with $20 \mathrm{~mm}$ triethanolamine buffer, $50 \mathrm{mM}-\mathrm{NaCl}, \mathrm{pH} 7.5$, before samples were loaded. Proteins were then eluted with the same buffer, and $1 \mathrm{ml}$ fractions were collected. Throughout the chromatography, protein content was monitored spectrophotometrically at $280 \mathrm{~nm}$. All fractions collected were assayed for proteinase activity using substrate PAGE.

Effect of inhibitors. Proteinase inhibitors (final concentrations 10$100 \mathrm{mM}$ ) were added to $100 \mu \mathrm{l}$ of cell extracts and culture supernatants and incubated at room temperature for $1 \mathrm{~h}$ before analysis by substrate
PAGE. Non-covalent inhibitors were added to the proteinase assay buffer during incubation of gels at $90^{\circ} \mathrm{C}$, at a final concentration of $10 \mathrm{~mm}$.

Thermostability of proteases. Cell-free culture supernatants samples $(100 \mu \mathrm{l})$ were sealed in capillary tubes (Barach \& Adams, 1977), and immersed in a paraffin oil bath at temperatures between $95^{\circ} \mathrm{C}$ and $125^{\circ} \mathrm{C}$. At appropriate time intervals, tubes were removed and immediately placed on ice. Residual proteinase activity was determined using substrate PAGE.

\section{Results and Discussion}

Static cultures of the hyperthermophilic archaeobacterium Pyrococcus furiosus were sampled for proteinase activity using azocasein as the proteolytic substrate. Proteinase activity was detected in both cell extracts and culture supernatants, reaching a peak at around $17-18 \mathrm{~h}$ after inoculation (Fig. $1 a$ and $b$ ). Proteinase production did not appear to be growth-phase dependent, as specific proteinase production (expressed as units of activity per g of protein) was observed to be linear throughout growth (Fig. $1 c$ ). Since the azocasein assay yields only the total titre of proteinase activity and provides no information on enzyme multiplicity, substrate-containing PAGE was used subsequently for more detailed analysis.

\section{Proteinase heterogeneity}

Using substrate-containing SDS-PAGE, a multiple band pattern of up to 13 distinct active proteinase monomers was observed in both cell extracts and culture supernatants, where apparent molecular masses ranged from $66 \mathrm{kDa}$ to $135 \mathrm{kDa}$ (Fig. 2). Levels of these active hydrolases were seen to increase until late exponential phase in a manner consistent with the analysis of total proteinase titres (Fig. $1 b$ ).

The observation of multiple proteinase bands from $P$. furiosus confirmed data obtained by Blumentals et al. (1990) and Eggen et al. (1990) who both report a multiple band pattern with the lowest molecular weight band being around $66 \mathrm{kDa}$. However, both groups describe the presence of only 5 proteinase bands.

The difference between our observations and those of Blumentals et al. (1990) and Eggen et al. (1990) lies in the sensitivity and resolution of the detection procedures used. Blumentals et al. (1990) reported extensive streaking and poor resolution of bands with gelatin-SDSPAGE and were thus forced to use a substrate gel overlay, from which only 5 bands were detected. On the other hand, Eggen et al. (1990) who also reported 5 bands, did not appear to have the problem of streaking in substrate gels. We can only conclude that the sensitivity and resolution of the substrate-containing SDS-PAGE technique may be dependent on details of its operation. 

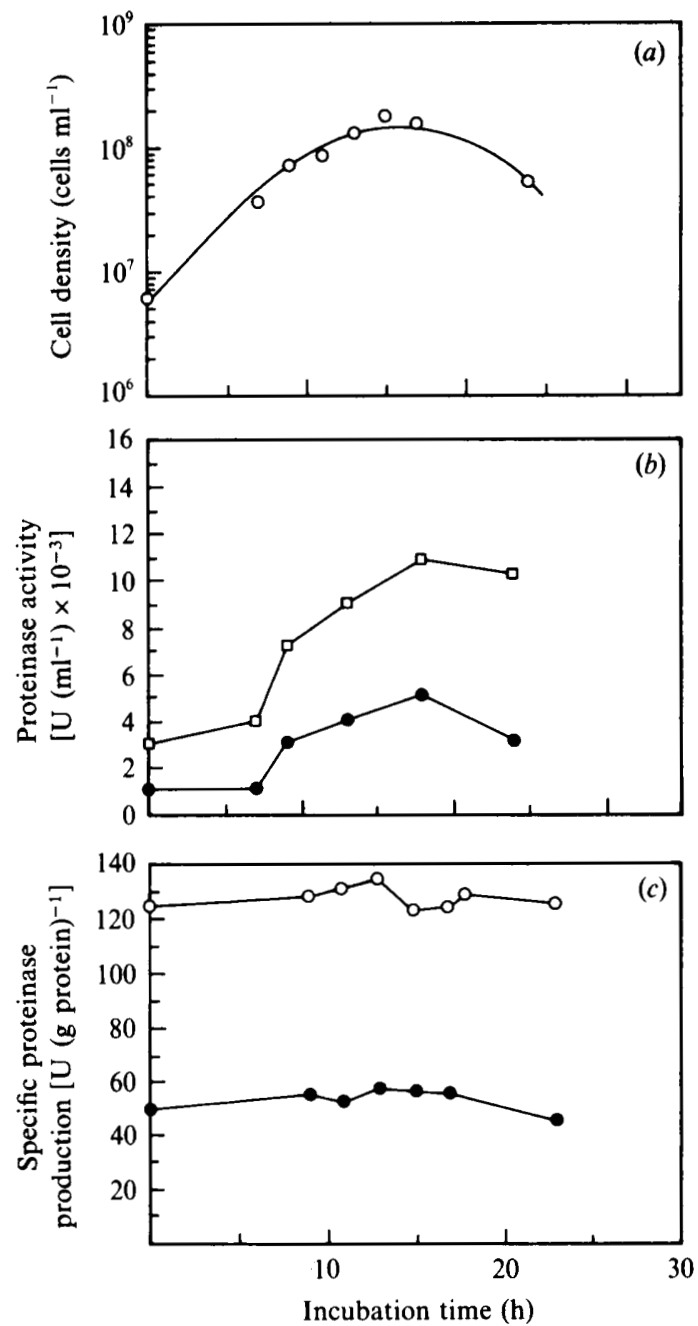

Fig. 1. Growth, proteinase activity and specific proteinase productivity of Pyrococcus furiosus. (a) Cell density; (b) proteinase activity in cell extract $(\bullet)$ and culture supernatant $(\square)$ fractions; and $(c)$ specific proteinase production in cell extract $(\bullet)$ and culture supernatant $(O)$ fractions.

Also, the reliance of the gel overlay detection method on diffusion of the enzyme will inevitably result in substantial loss of resolution and detection. We note that the substrate concentration used by us, Blumentals $e t$ al. (1990) and Eggen et al. (1990) was found to differ as much as 50 -fold.

There are a number of possible origins of a multiplicity of discrete activity bands in substrate-containing SDSPAGE gels. These might include: (i) active processing products from larger species, such as proteolytic or autolytic degradation products; (ii) artefacts resulting from incomplete unfolding; (iii) artefacts resulting from heterogeneous associations with the substrate during electrophoresis; and (iv) discrete genetically distinct polypeptides. We shall consider each of these possible mechanisms in turn.

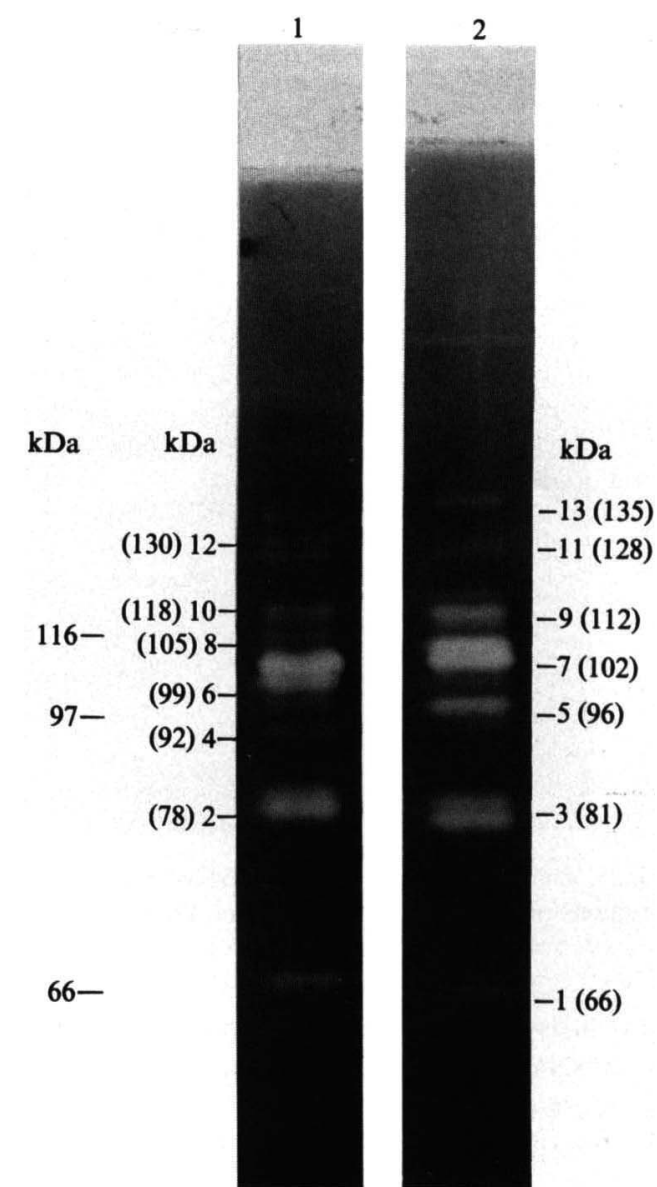

Fig. 2. Proteinase multiplicity from $P$. furiosus. Lane 1, cell extract fraction; lane 2, culture supernatant fraction. Numbers on RHS and LHS of photograph indicate band numbers in ascending molecular mass (indicated in brackets), whereas numbers on the far LHS denote molecular masses of standard markers $(66 \mathrm{kDa}$, bovine serum albumin; $97 \mathrm{kDa}$, phosphorylase $\mathrm{b}$; $116 \mathrm{kDa}, \beta$-galactosidase).

The generation of heterogeneous active proteinase fragments by proteolytic or autolytic degradation is known to occur (Fontana, 1988). However, preincubation of Pyrococcus cell-free culture supernatants and cell extract samples at different temperatures $\left(4^{\circ} \mathrm{C}, 20^{\circ} \mathrm{C}\right.$, $60{ }^{\circ} \mathrm{C}$ and $95^{\circ} \mathrm{C}$ ) for up to $24 \mathrm{~h}$ before analysis by substrate PAGE, showed no activity bands of $<66 \mathrm{kDa}$ (data not shown). Also, banding patterns identical to those in Fig. 2 were observed with negligible loss of apparent activity for any proteinase. If significant autolysis did occur, then a gradual decrease in the highermolecular-mass bands, possibly corresponding to an increase in the lower-molecular-mass bands, might be observed over time. Under no conditions did we observe this behaviour, suggesting that the activity bands were unlikely to be degradation products. 


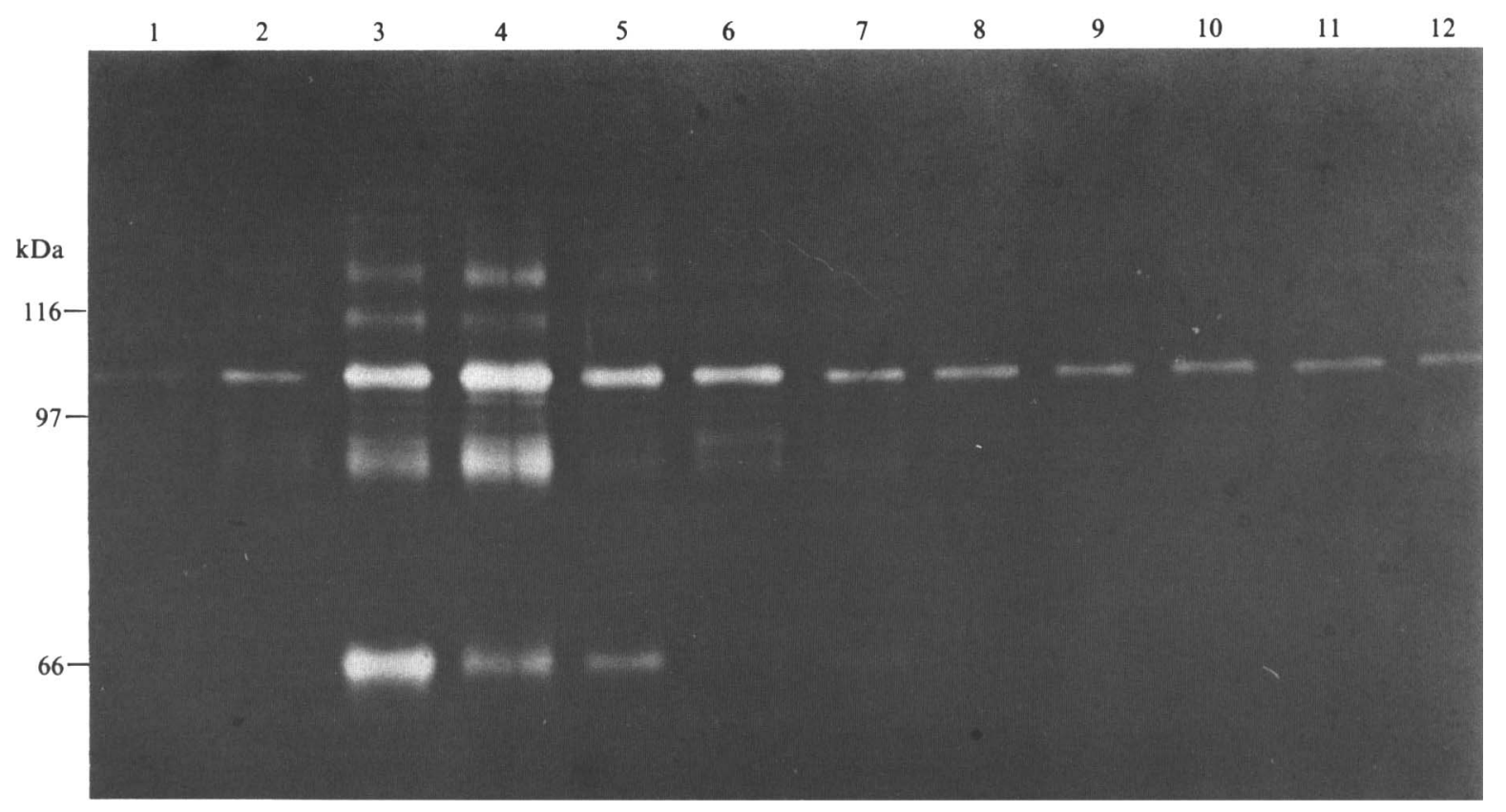

Fig. 3. Gelatin-containing SDS-PAGE of fractions from FPLC gel permeation using Superose 12 HR 10/30. Lanes 1 to 12 represent fractions obtained from a cell extract. Numbers on LHS denote molecular masses of standard markers.

These results are therefore at odds with data obtained by Blumentals et al. (1990) from immunoblot studies in which a decrease in the molecular mass of a $66 \mathrm{kDa}$ proteinase to an inactive proteolytic fragment of $49 \mathrm{kDa}$ was observed after a $24 \mathrm{~h}$ incubation in $1 \%(\mathrm{w} / \mathrm{v})$ SDS. In the case of Eggen et al. (1990), preincubation of 'pyrolysin' at $95^{\circ} \mathrm{C}$ in the absence of substrate at different times, followed by activity staining using gelatin PAGE, showed a concomitant increase in intensity of the lower-molecular-mass bands to $65 \mathrm{kDa}$, suggesting processing of higher-molecular-mass proteinases. However, our results, obtained under similar experimental conditions, did not show this increase in intensity of the $66 \mathrm{kDa}$ band. In fact, a slight decrease in intensity of the $66 \mathrm{kDa}$ band was observed after $20 \mathrm{~h}$, which clearly does not support the view that this band is a proteolytic degradation product of high-molecularmass proteins (Eggen et al., 1990).

Incomplete protein unfolding prior to electrophoresis can be a major cause of artefacts in substrate gels (Horie et al., 1984; Kelleher \& Juliano, 1984). Partially unfolded proteins can retain activity and hence interact with the substrate during electrophoresis, retarding mobility and thereby producing multiple bands and streaking across gels. Proteinases which are resistant to SDS will also remain active and cause streaking in substrate gels. This phenomenon was observed by Blumentals et al. (1990) who found that of the five native proteinases identified from $P$. furiosus cell extracts, two of these had shown SDS resistance, causing streaks on gelatin-containing gels.
Further characterization of these bands showed these to be true enzymes and not artefacts.

However, we observed a significantly different response of Pyrococcus proteinases to SDS. In our hands, no evidence of SDS resistance was obtained, despite using a variety of treatment conditions (variations of time, temperature and SDS concentration; data not shown). We draw this conclusion from the total absence of streaking and the consistently reproducible band patterns as seen in Fig. 2.

An alternative, albeit unlikely, source of artefactual banding multiplicity might arise from heterogeneous non-specific interactions, during electrophoresis, between denatured protein and gel-encapsulated substrate. However, our observation that casein-containing SDSpolyacrylamide gels produce multiple band patterns of high resolution, similar to those seen with gelatincontaining gels, is strong evidence that the apparent proteinase multiplicity does not arise from some heterogeneous interaction with the substrate during electrophoresis.

These data contribute to the conclusion that the bands observed are discrete polypeptides. However, the question as to whether these bands are genetically related still remains. From immunoblot studies, Blumentals et al. (1990) have shown that proteinases S66 and S102 are not related, and correspond to different enzymes. These proteinases were also found to be distinct from the other three proteinases present in $P$. furiosus cell extracts. Our data support this contention and suggest the existence of 


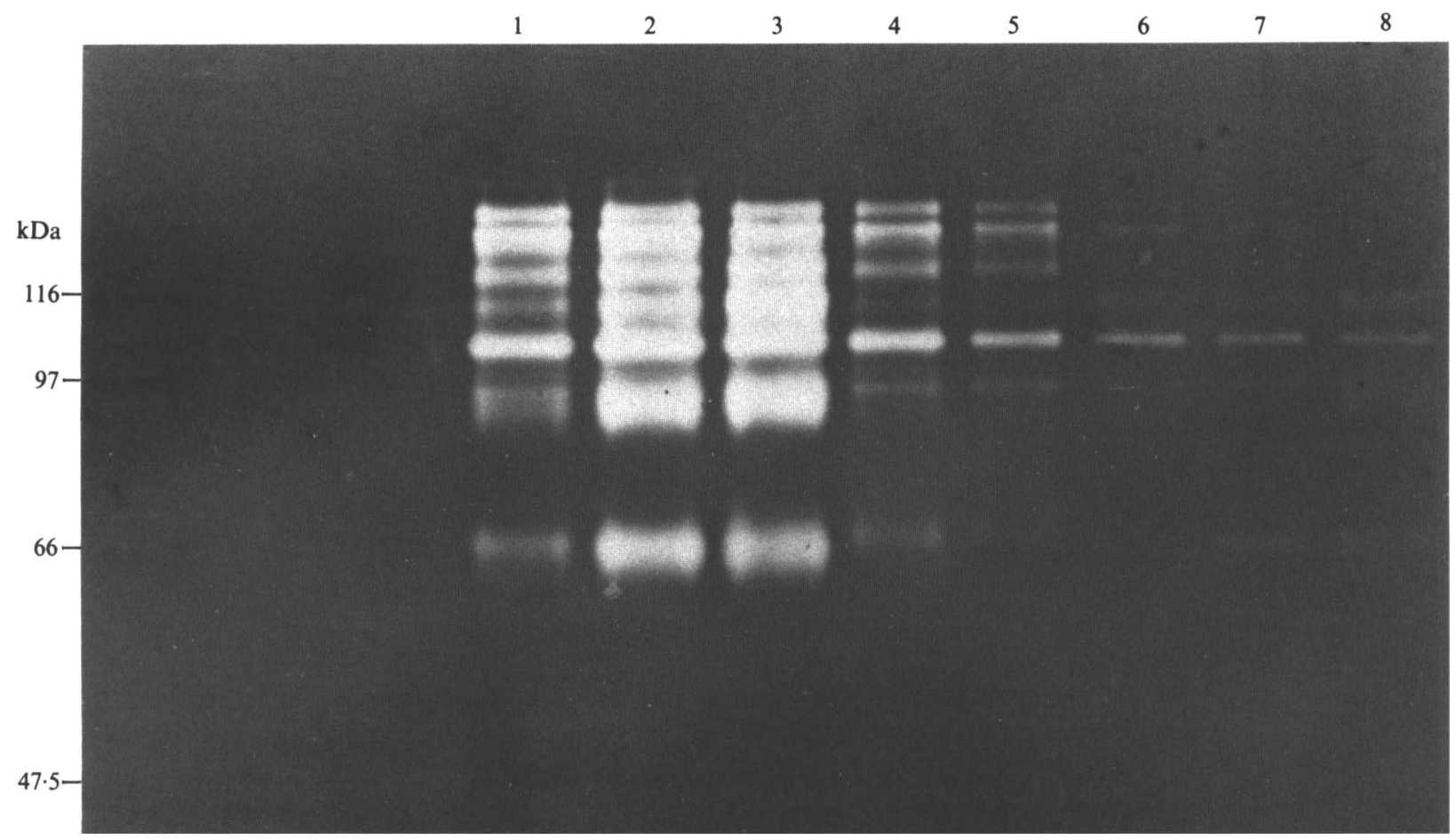

Fig. 4. Sucrose density gradient fractions analysed using gelatin-SDS-PAGE. Portions of cell extract $(500 \mu \mathrm{l})$ were loaded and run on a $6-30 \%(w / v)$ sucrose gradient (see Methods section). Fractions collected were run alongside standard markers on gelatin-SDS-PAGE. Gels were renatured and incubated for $3 \mathrm{~h}$ at $90^{\circ} \mathrm{C}$, before staining with Coomassie Blue. Lanes 1 to 8 represent fractions from sucrose density gradient runs.

additional discrete peptides. Eggen et al. (1990), on the other hand, contend that the multiple protease bands from 'pyrolysin' are processed to give a final proteolytically active $66 \mathrm{kDa}$ band. Neither our data, nor that of Blumentals et al. (1990), support this conclusion.

\section{In vivo state of proteinase monomers}

Non-denaturing (native) PAGE indicated the presence of more than 7 proteinases from cell extracts and culture supernatants. Analysis of native gels of varying acrylamide concentrations (5-10\% acrylamide) gave apparent molecular masses of between 95 and $280 \mathrm{kDa}$ (data not shown).

Separation of cell extracts by FPLC gel permeation chromatography and sucrose density centrifugation produced 2 higher-molecular-mass proteinases of approximately 185 to $200 \mathrm{kDa}$ (from sucrose gradients, sedimentation coefficients of $9.5 \mathrm{~S}$ and $10 \mathrm{~S}$ respectively) and 200 to $280 \mathrm{kDa}$ (FPLC) from cell extracts and culture supernatants. When subsequently analysed by substrate-containing SDS-PAGE, these high-molecularmass active proteinases showed an identical pattern to that observed previously (Figs 3 and 4). The most probable explanation for these results is that the individual proteinases interact (either in vivo or in vitro) to form high-molecular-mass active aggregates. We have no evidence to confirm the existence of these aggregates in vivo, although the appearance of multiple bands on native PAGE might argue for an in vitro aggregation phenomenon (Figs 3 and 4).

\section{Inhibitors}

All but one of the 13 proteinase bands from Pyrococcus showed complete inhibition by $10 \mathrm{~mm}$-phenylmethylsulphonyl fluoride (PMSF) suggesting predominance of serine-type proteinases (data not shown). There was no significant change in activity after treatment with the thiol proteinase inhibitor iodoacetamide. Partial inhibition by the metal chelator EDTA $(10 \mathrm{mM})$ was observed with the PMSF-insensitive band (130 kDa), suggesting a requirement of metal ions for activity. The results of inhibition studies obtained for the additional bands support the data obtained by Blumentals et al. (1990) and Eggen et al. (1990), who both classify the 5 bands reported in their work as serine-type proteinases. 

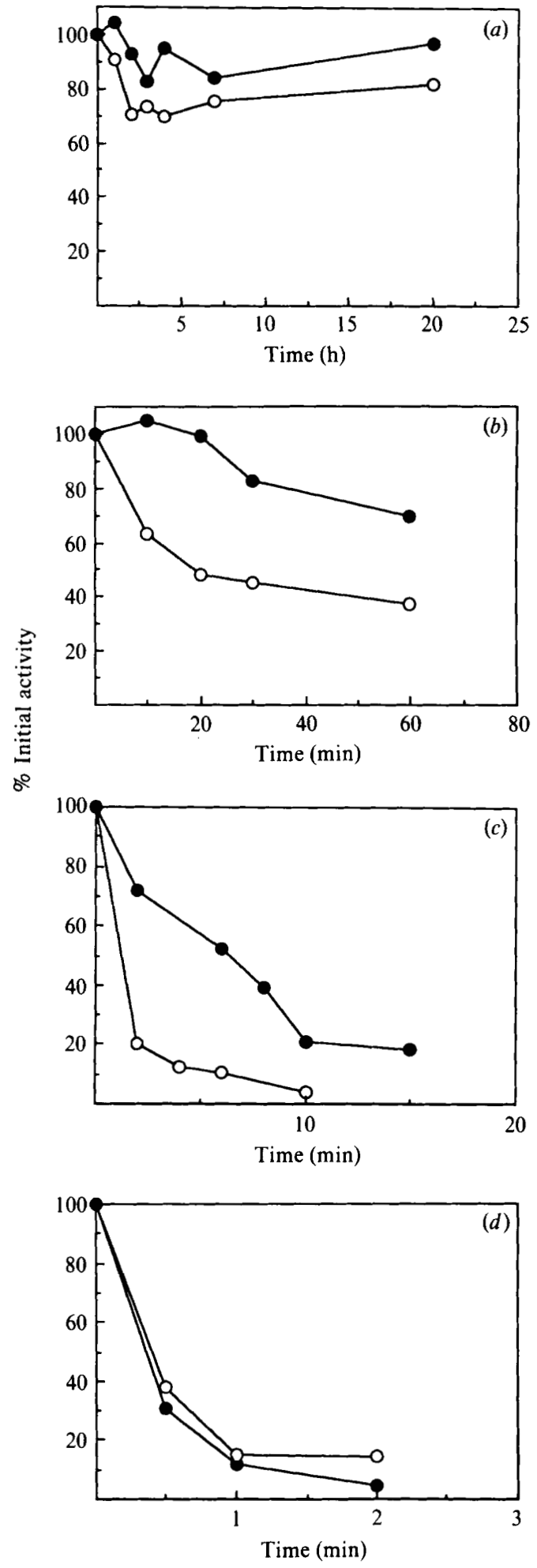

Fig. 5. Thermostability profiles for Pyrococcus $66 \mathrm{kDa}$ proteinase at various temperatures. Culture supernatant samples $(100 \mu 1)$ were incubated at $(a) 95^{\circ} \mathrm{C},(b) 105^{\circ} \mathrm{C},(c) 115^{\circ} \mathrm{C}$, and $(d) 125^{\circ} \mathrm{C}$, with (O) and without $(O)$ the addition of $10 \mathrm{mM}-\mathrm{CaCl}_{2}$. Samples were removed at appropriate intervals, cooled and assayed for activity using gelatinSDS-PAGE (see Methods).
Table 1. Apparent half life values of the $66 \mathrm{kDa}$ proteinase from $P$. furiosus with and without $10 \mathrm{~mm}-\mathrm{CaCl}_{2}$

\begin{tabular}{ccc}
\hline & \multicolumn{2}{c}{ Half life $\left(\mathrm{t}_{1 / 2}\right)$} \\
\cline { 2 - 3 } Temperature $\left({ }^{\circ} \mathrm{C}\right)$ & Without calcium & With calcium \\
\hline 95 & $>20 \mathrm{~h}$ & $>20 \mathrm{~h}$ \\
105 & $15 \mathrm{~min}$ & $117 \mathrm{~min}$ \\
115 & $52 \mathrm{~s}$ & $6.3 \mathrm{~min}$ \\
125 & $22 \mathrm{~s}$ & $20 \mathrm{~s}$ \\
\hline
\end{tabular}

\section{Thermostability}

At temperatures between $95^{\circ} \mathrm{C}$ and $105^{\circ} \mathrm{C}$, all 13 proteinases demonstrated a high degree of stability, with some proteinases showing enhanced stability in the presence of $10 \mathrm{~mm}-\mathrm{CaCl}_{2}$ (Fig. 5). Using gelatin-SDSPAGE as a semi-quantitative assay, the apparent half life values of the $66 \mathrm{kDa}$ protein (selected as this appeared to be one of the most stable) calculated from first order constants (Moore, 1962) were considerably increased when calcium was added, suggesting that this metal ion is required to stabilize the protein structure and prevent unfolding at higher temperatures (Table 1).

The value obtained for the $66 \mathrm{kDa}$ proteinase exceeds the half life values of other known archaeobacterial proteinases such as archaelysin, $t_{1 / 2}\left(95^{\circ} \mathrm{C}\right), 70-90$ minutes (Cowan et al., 1987), and thermopsin, $t_{1 / 2}$ $\left(80^{\circ} \mathrm{C}\right), 48$ hours (Lin \& Tang, 1990). Blumentals et al. (1990) have reported that the $66 \mathrm{kDa}$ proteinase from Pyrococcus was found to have a half life of about $33 \mathrm{~h}$ at $98^{\circ} \mathrm{C}$, making this the most stable proteinase to date.

\section{Concluding remarks}

In this study, up to 13 active proteolytic polypeptides from $P$. furiosus have been identified. We believe that the heterogeneity of these enzymes is valid from the evidence presented, despite conflicting evidence of 5 active bands obtained from studies by Blumentals et al. (1990) and Eggen et al. (1990). We also suggest that these active proteinases are not artefacts, but arise from the dissociation of larger multimeric proteinases.

The question that is automatically raised is why so many proteinases are produced from a hyperthermophile. It is known that multiple heterogeneous intracellular proteinases serve a wide variety of functions including protein turnover, nutritional and specific posttranslational modification events. When information is available on the peptide bond specificity of individual proteinases, it may be possible to imply one or other function. However, at present the specific function for these $\boldsymbol{P}$. furiosus proteinases remains unknown. 


\section{References}

BaraCH, J. T. \& ADAMS, D. M. (1977). Thermostability at ultrahigh temperatures of Thermolysin and a protease from a psychrotrophic Pseudomonas. Biochimica et Biophysica Acta 485, 417.

Blumentals, I. I., Robinson, A. S. \& Kelly, R. M. (1990). Characterization of SDS-resistant proteolytic activity in the hyperthermophilic archaebacterium Pyrococcus furiosus. Applied and Environmental Microbiology 56, 1992-1998.

Bryant, F. O. \& ADAmS, M. W. W. (1989). Characterization of hydrogenase from the hyperthermophilic archaebacterium, Pyrococcus furiosus. Journal of Biological Chemistry 264, 5070-5079.

Clarke, J. T. (1964). Simplified 'disc' (polyacrylamide gel) electrophoresis. Annals of the New York Academy of Sciences 121, 4284.35.

Cowan, D. A. \& Daniel, R. M. (1982). Purification and some properties of an extracellular protease (caldolysin) from an extreme thermophile. Biochimica et Biophysica Acta 705, 293305.

Cowan, D. A., Smolenski, K. A., Daniel, R. M. \& Morgan, H. W. (1987). An extremely thermostable extracellular proteinase from the strain of the archaebacterium Desulfurococcus growing at $88^{\circ} \mathrm{C}$. Biochemical Journal 247, $121-133$.

Davis, B. J. (1964). Disc electrophoresis-II. Method and application to human serum proteins. Annals of the New York Academy of Sciences 121, 404427.

Eggen, R., Geerling, A., Watts, J. \& M. DE Vos, W. (1990). Characterization of pyrolysin, a hyperthermoactive serine protease from the archaebacterium Pyrococcus furiosus. FEMS Microbiology Letters 71, 17-20.

Fiala, G. \& Stetter, K. O. (1986). Pyrococcus furiosus sp. nov., represents a novel genus of marine heterotrophic archaebacteria growing optimally at $100^{\circ} \mathrm{C}$. Archines of Microbiology 145, 56-61.
Fontana, A. (1988). Structure and stability of thermophilic enzymes. Studies on thermolysin. Biophysical Chemistry 29, 181-193.

Hanner, M.. Redl, B. \& Stoffler, G. (1990). Isolation and characterization of an intracellular aminopeptidase from the extreme thermophilic archaebacterium Sulfolobus solfataricus. Biochimica et Biophysica Acta 1033, $148-153$.

Horie, N., Fukuyama, K., Ito, Y. \& Epstein, W. L. (1984). Detection and characterization of epidermal proteinases by polyacrylamide gel electrophoresis. Comparative Biochemistry and Physiolog! 77B. 349-353.

Kelleher, P. J. \& Juliano, R. L. (1984). Detection of proteases in polyacrylamide gels containing covalently bound substrates. Analytical Biochemistry 136, 470-475.

Laemmli, U. K. (1970). Cleavage of structural proteins during the assembly of the head of bacteriophage T4. Nature, London 227 , $680-685$

Lin, X.-L. \& TANG, J. (1990). Purification, characterization and genc cloning of Thermopsin, a thermostable acid protease from Sulfolohus acidocaldarius. Journal of Biological Chemistry 265, 1490-1495.

Martin, R. G. \& Ames, B. N. (1961). A method for determining the sedimentation behaviour of enzymes: Applications to protein mixtures. Journal of Biological Chemistry 236, 1.3721379.

Moore, W. J. (1962). Physical Chemistry, 4th edn, pp. 260-263. London: Longman.

Owusu, R. K. \& Cowan, D. A. (1989). Correlation between microbial protein thermostability and resistance to denaturation in aqueous organic solvent 2-phase systems. Enzyme and Microbial Technology. 11, $568-574$

Veronese, F. M., Boccu, E., Schiavon, C., Grandi, C. \& Fontana, A. (1984). General stability of thermophilic enzymes. Studies on 6phosphogluconate dehydrogenase from Bacillus stearothermophilus and yeast. Journal of Applied Biochemistry 6, 3947. 